\title{
Nasal deformities resulting from flow driver continuous positive airway pressure
}

\author{
N J Robertson, L S McCarthy, P A Hamilton, A L H Moss
}

\begin{abstract}
Over a period of six months, seven cases were documented of trauma to the nose as a result of flow driver continuous positive airway pressure in babies of very low birthweight (VLBW). There was a complication rate of $20 \%$ in the babies who required it. Deformitiesconsisted of columella nasi necrosis which can occur within three days, flaring of nostrils which worsens with duration of continuous positive airway pressure, and snubbing of the nose which persists after prolonged continuous positive airway pressure.

These complications should be preventable by modifications to the mechanism and method of use.
\end{abstract}

(Arch Dis Child 1996;75:F209-F212)

Keywords: flow driver continuous airway pressure, columella nasi necrosis, weaning, respiratory distress syndrome.

Gregory et al first reported the efficacy of continuous positive airway pressure as a treatment for respiratory distress syndrome in $1971 .^{12}$ Today continuous positive airway pressure is used to wean babies off ventilators, and for apnoea of prematurity. It facilitates extubation in babies of $<1500 \mathrm{~g},{ }^{34}$ although Greenough et $a l^{5}$ found no difference in babies weaned off

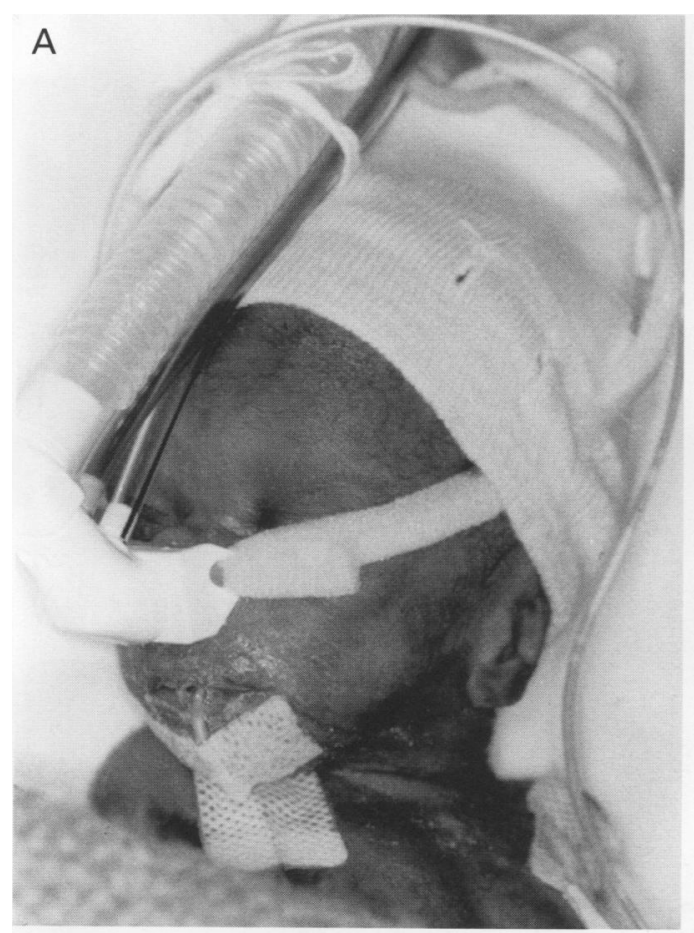

Figure $1 A$ Application of flow driver continuous positive airway pressure to a premature baby. nasal prong in current use.

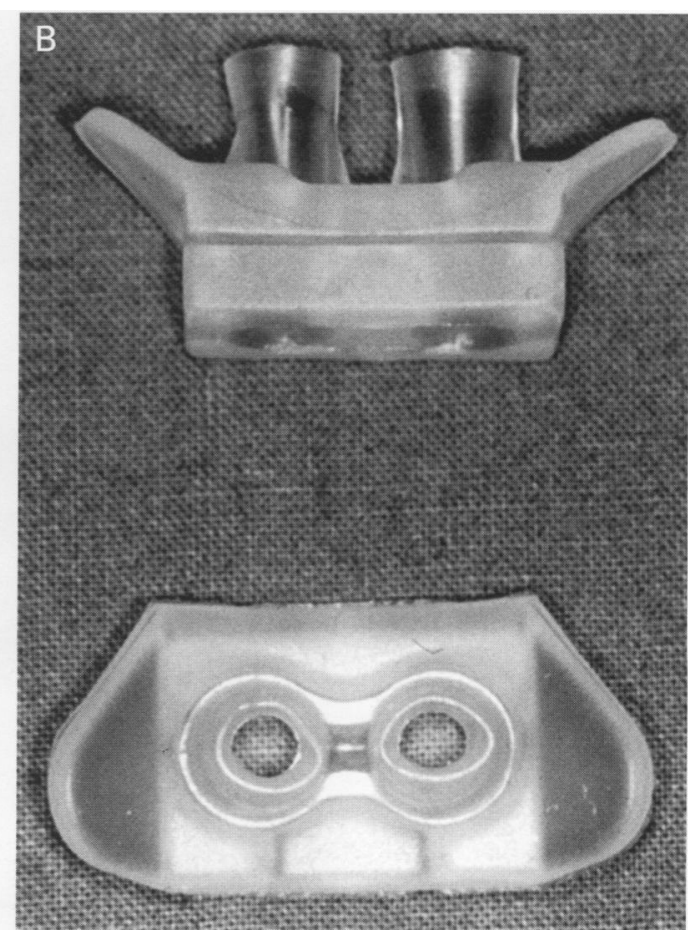

positive pressure ventilation (PPV) using continuous positive airway pressure or headbox. Chronic intubation has been associated with subsequent subglottic stenosis, tracheal stenosis, secondary infections and aspiration. ${ }^{6}$ Continuous positive airway pressure lowers the rate of subsequent bronchopulmonary dysplasia in preterm infants. ${ }^{7}$ Early weaning, therefore, should decrease the incidence of these complications.

Various devices have been developed to deliver continuous positive airway pressure, including a positive pressure hood, a face mask, and a tracheal tube used as a "long prong" The binasal prong was first introduced to deliver continuous positive airway pressure in 1973 by Agostino et al. ${ }^{8}$ Two short wide prongs should provide better pressure delivery than one long endotracheal tube, as resistance is proportional to length and inversely proportional to radius. Disadvantages of conventional long prong continuous positive airway pressure include flow starvation, ineffective pressure control secondary to mechanical resistance, and intolerance of feeds due to gastric distension. These are largely overcome by the "fluidic flip" mechanism of the flow driver continuous positive airway pressure device manufactured by EME Ltd (Electrical Medical Equipment). Inlet and outlet channels assist expiratory flow, decrease respiratory resistance,

(B) The shape of the 

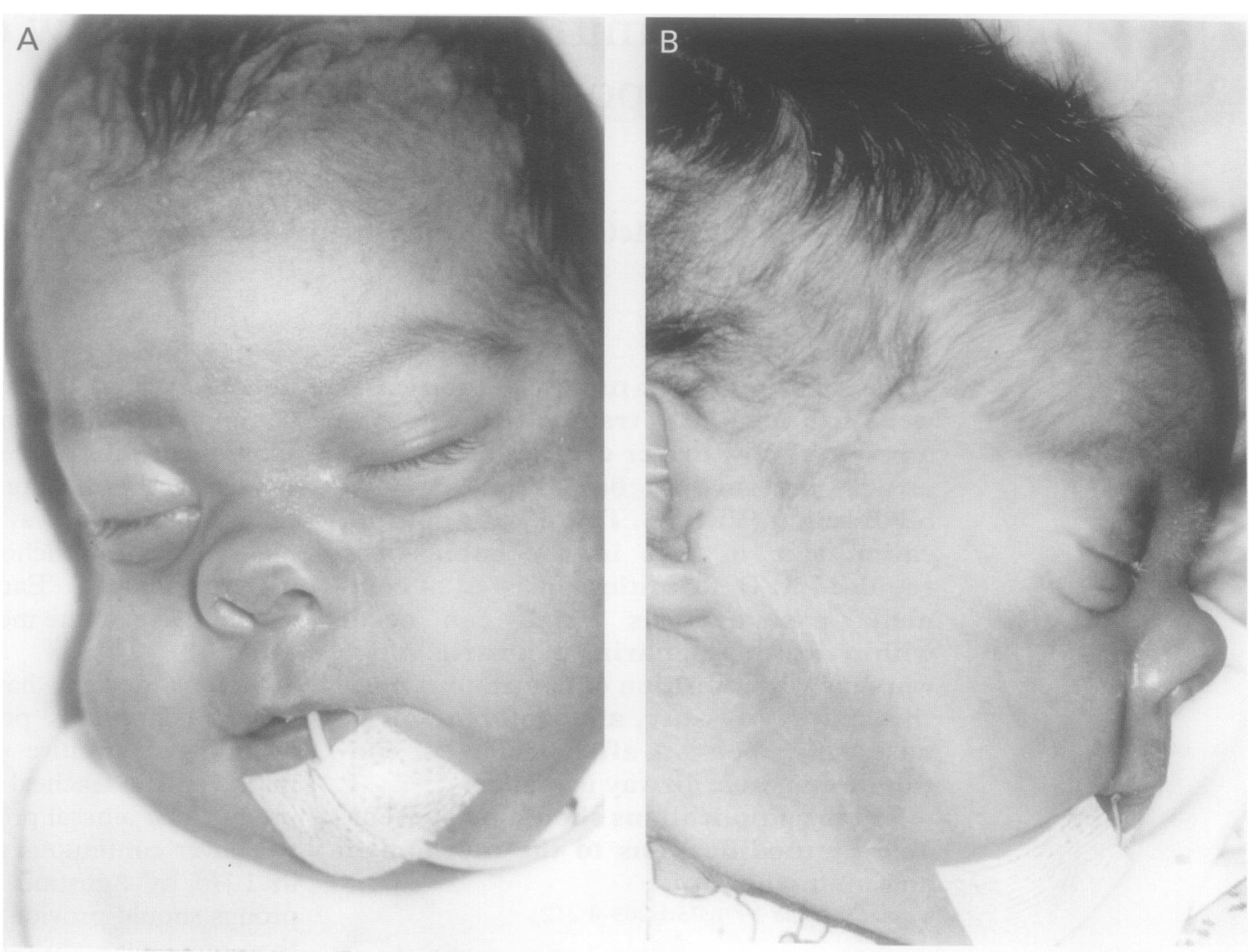

Figure 2(A and B) Case 1: severe nasal snubbing after prolonged flow driver continuous positive airway pressure. Gestation 24 weeks, birthweight $835 \mathrm{~g}, P P V 28$ days, flow driver/headbox 60 days

and decrease the work of breathing. Flow driver continuous positive airway pressure involves the application of a silastic block with short prongs to the nose of the infant (fig 1A). It is held in place with straps which pass around the head. An airtight seal is needed to

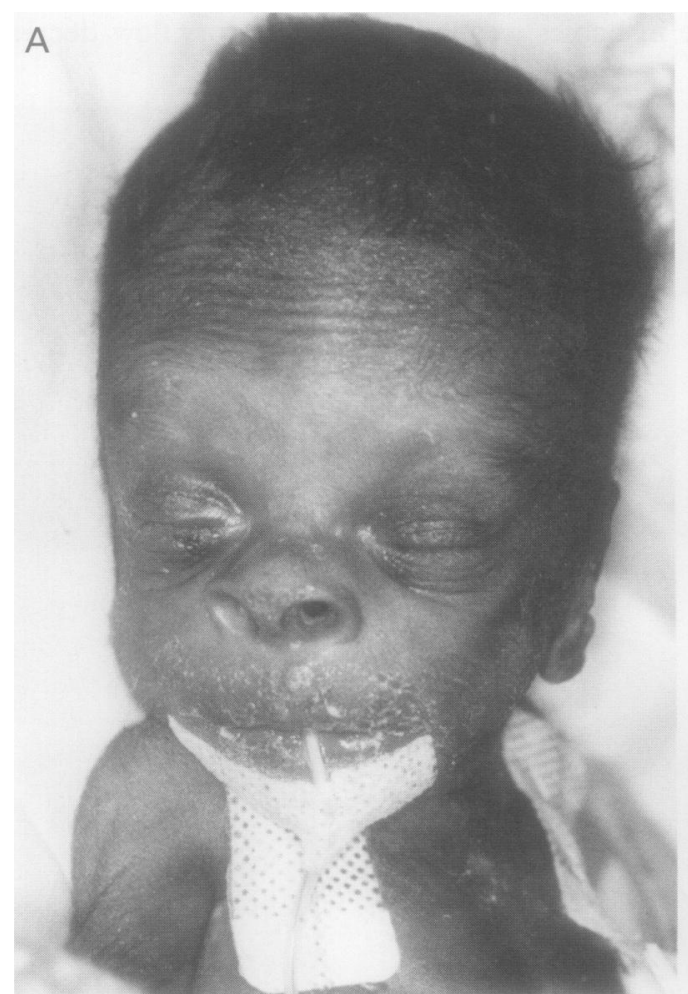

prevent loss of positive pressure. The seal is made at the tip of the prongs.

Flow driver continuous positive airway pressure has been in use in our neonatal unit for three years for weaning off ventilatory support and is alternated with periods of headbox oxy-

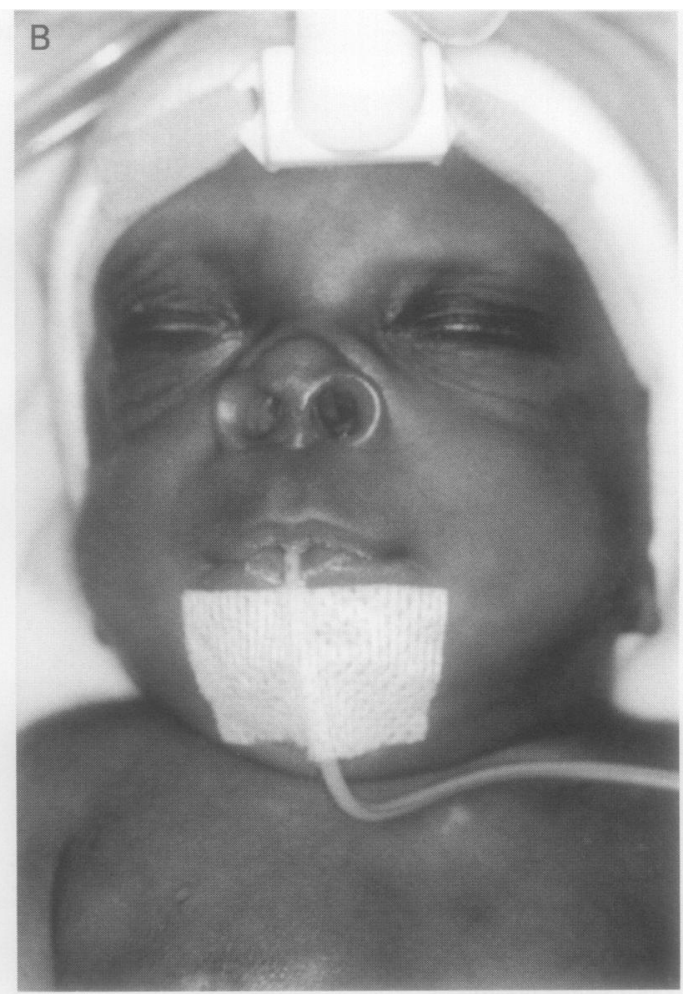

Figure 3A Case 2: flaring of nostrils after four weeks; (B) case 2: progressive flaring of nostrils, circular distortion of nares and flattening of alar ridges after prolonged flow driver continuous positive airway pressure at three months. Gestation 26 weeks, birthweight $632 \mathrm{~g}$, PPV nine days, flow driver/headbox 41 days 

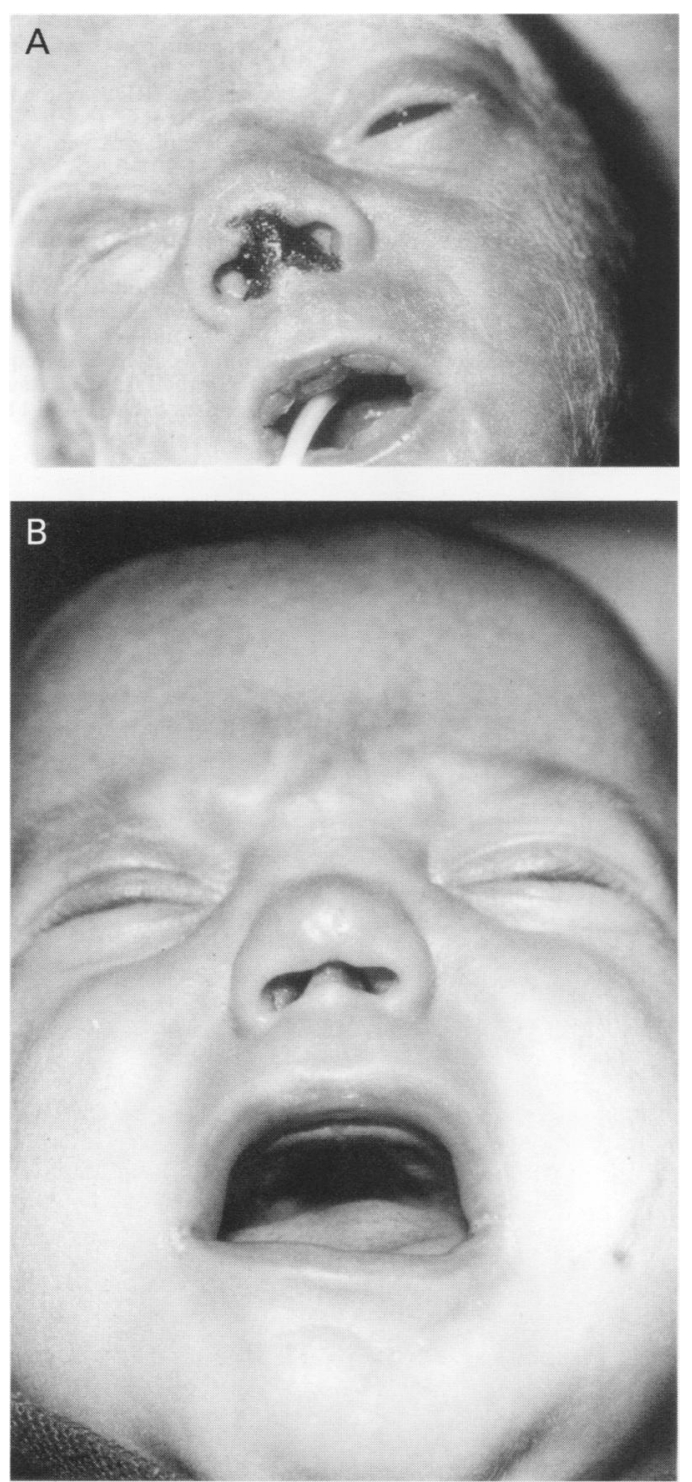

Figure 4A Case 3: columella necrosis after three days; (B) progression to absent columella at 4 months of age. Nasal septal damage occurred after three days of flow driver continuous positive airway pressure. Columella necrosis progressed to septal necrosis. At 4 months of age columella was absent. Gestation 28 weeks, birthweight $1164 \mathrm{~g}, \mathrm{PPV}$ five days, flow driver/headbox seven days

gen. During the period, June to November 1995, there were 302 admissions to the neonatal unit of which 74 were VLBW. Seven cases of nasal trauma were noted out of the 35 babies who required flow driver continuous positive airway pressure.

Flow driver continuous positive airway pressure was seen to cause:

(1) Snubbing of the nose: this becomes severe after prolonged treatment ( 60 days) (case 1)(fig 2).

(2) Flaring of the nostrils: the nasal rim becomes circular. This deformity worsens the longer the duration of continuous positive airway pressure (case 2) (fig 3).

(3) Columella nasi necrosis which can progress to include septal necrosis: this can occur after as little as three days (case 3 ) (fig 4).

\section{Comment}

It is only in the past 30 years that intubation has become routine in the management of res- piratory difficulties in infants and children. Jackson Rees et al in $1966^{\circ}$ described a modified nasotracheal tube which permitted prolonged intermittent positive pressure ventilation in infants and children as an alternative to management by tracheostomy. Nasal deformities following prolonged nasotracheal intubation have been widely reported ${ }^{10}$ and consist of unilateral stenosis of the nares and septal erosion. In $1980^{11}$ Gowdar et al reported an incidence of nasal deformity of $50 \%$ following nasotracheal intubation in babies weighing less than $1000 \mathrm{~g}$ and who had been intubated for more than seven days; but no nasal deformity was seen with nasal continuous positive airway pressure. This may reflect the fact that in the mid 1970s, when the data were collected, continuous positive airway pressure was used on a short term basis and in healthier infants, while today we tend to use continuous positive airway pressure earlier, in babies who are smaller, and for longer periods.

As far as we are aware, there has been no previous documentation of nasal deformity as a result of flow driver continuous positive airway pressure. The seven cases reported here represent a complication rate of $20 \%$ in babies weighing under $1500 \mathrm{~g}$ at birth.

The shape of the prong used in continuous positive airway pressure is not anatomical. The base does not allow for projection of the columella beyond the alar rim. The prongs are perpendicular to the base, not converging as the baby's nasal passages do, and the base of the prongs are closest together where the columella is widest. A curved design that has tapering nasal prongs would be better. Plastic surgical reconstruction of the columella in children is difficult. A composite graft from the earlobe may be used to avoid scars in the nasolabial region. ${ }^{12}$

The manufacturers are aware of the complications we have experienced and we are working together to modify the design of the prong. In the meantime, they have recommended the following: (1) Ensure appropriate fit of prongs to baby's nose; particularly avoid the use of prongs and hats which are too small. (2) Tie the hats to the prongs more horizontally, preventing the upward pull on the nose. (3) Decrease the weight of the tubing pulling on the nose by ensuring that it is supported. (4) Rest the nose for half an hour every 4 to 6 hours. (5) If the nose looks red and tender, use Granuflex under the prong device. (6) Refresher training sessions for nursing staff with particular emphasis on fixation.

Continuous positive airway pressure is widely used and may be beneficial in weaning small babies off PPV. The clinically important complications we have noted should be preventable by modifications to the mechanism and method of use.

1 Gregory GA, Joseph MD, Kitterman MD. Treatment of the idiopathic respiratory distress syndrome with continuous positive airway pressure. $N$ Engl $\mathcal{F}$ Med 1971;284:333-40.

2 Delivoria-Papadopoulos M, Levison H, Swyer PR. Intermittent positive pressure respiration as a treatment in severe 
respiratory distress syndrome. Arch Dis Child 1965;40:474-8.

3 Higgins RD, Richter SE, Davis JM. Nasal continuous positive airway pressure facilitates extubation of very low birth weight neonates. Pediatrics 1991;88:999-1003.

4 So BH, Tamura M, Mishina J. Application of nasal continuous positive airway pressure to early extubation in very low ous positive airway pressure to early extubation in very

5 Chan V, Greenough A. Randomised trial of methods of extubation in acute and chronic respiratory distress. Arch

6 Goodwin SR, Graves SA, Haberkern CM. Aspiration in itubated premature infants. Pediatrics 1985;75:85-8.

7 Avery ME, Tooley WH, Keller JB, Hurd SS, Bryan MH, Cotton RB, et al. Is chronic lung disease in low birth weight infants preventable? A survey of eight centres. Pediatrics 1987;79:26-30.
8 Agostino R, Orzalesi M, Nodari S, Mendicini M, Conca L, Savignoni $\mathrm{p}$, et al. Continuous positive airway pressure (CPAP) by nasal cannula in the respiratory distress syndrome (RDS) of the newborn. Pediatr Res 1973;7:50.

9 Jackson Rees G, Owen-Thomas JB. A technique of pulmonary ventilation with a nasotracheal tube. $B r \mathcal{F}$ Anaesth 1966;38:901-6.

10 Baxter RI, Johnson JD, Goetzman BW, Hackel A. Cosmetic nasal deformities complicating prolonged nasotracheal intubation in critically ill newborn infants. Pediatrics 1995;55:884-7

11 Gowdar K, Bull MJ, Schreiner RL, Lemons JA, Gresham EL. Nasal deformities in neonates. Am $\mathcal{F}$ Dis Child 1980;134:954-7.

12 Barton FE, Byrd HS. Acquired deformities of the nose. In McCarthy LS: McCarthy Plastic Surgery Philidelphia: WB Saunders \& Co, 1990: 1124-2008. 